\title{
Impact Of An Educational Program On Nurses' knowledge Related To Care Of Patients With Chest Tube
}

\author{
Prof. Nabila A. Bedier, Dr. Amal Bakr Abo EL-Ata, Noha Mohammed Ibrahim \\ Department of Medical Surgical Nursing, Faculty of Nursing, Alexandria University, \\ Department of Medical Surgical Nursing, Faculty of Nursing, Port Said University, \\ Department of Medical Surgical Nursing, Faculty of Nursing, Port Said University.
}

\begin{abstract}
A chest tube is a valuable tool for the treatment of various pathologic conditions of the pleural space. Also, chest tube performed as a planned procedure post surgery or as a life saving emergency procedure. The study aimed to evaluate the impact of an educational program on nurses' knowledge related to care of patients with chest tube. A quasiexperimental design was used in the current study. The study was carried out on a convenient sample of 30 nurses working in intensive cardiothoracic unit, cardiothoracic care unit, and general surgical unit at Ismailia University Hospital. Data were obtained through; nurses' knowledge questionnaire. The educational program was designed based on an extensive revision of the related materials, recent medical textbooks, studies and literature. Results of this study indicated that $96.7 \%$ of studied nurses had statistically significant unsatisfactory level of knowledge pre program implementation. The statistically significant level of improvement in nurses' knowledge $\mathrm{P}<0.0001 * * *$ was very high immediately after the program implementation and there was decline in the studied nurses' total knowledge scores throughout the first follow -up and second fellow up after program implementation but it showed significant improvement than pretest $(\mathrm{P}=1.0, \mathrm{P}<0.0001$ respectively $)$. The study concluded that there was statistically significant improvement immediately after program implementation and throughout the follow up phases regarding nurses' knowledge related to care of patients with chest tube. The study recommended that regular continuous educational program should be designed to give information about chest tube for enhancing and reinforcement of nurses' knowledge to achieve high quality care.
\end{abstract}

Key words: Educational program, Nurses, Knowledge, Care, Chest tube. 


\section{Introduction}

Chest tubes are very simple and effective tools in the management of thoracic and pleural pathology. They need proper safe insertion and correct management, chest tubes are inserted to remove pathological collections of air or fluid in the pleural space, to allow the re-creation of the essential negative pressures in the chest, and to permit complete expansion of the lung, thereby restoring normal ventilation (Rajan, 2013).

There are several complications that can develop from chest tube, the most serious complications resulting from chest tube placement is tension pneumothorax which can develop if there is any obstruction in the chest tube drainage system. Chest tube complication also include bleeding from an injured intercostals artery perforation, perforation of visceral organs (lung, heart, diaphragm, or intra-abdominal organs), perforation of vascular structures such as the aorta or subclavian vessels, intercostals neuralgia due to trauma of neuro-vascular bundles, subcutaneous emphysema, re-expansion pulmonary edema, infection of the drainage site, pneumonia, and empyema. There may be technical problems such as intermittent tube blockage from clotted blood, pus or debris and incorrect positioning of the tube (Shalmovitz, 2011).

Most often the nursing management of patient with a chest tube has received little attention. After a chest tube is inserted; nurses are responsible persons for managing the chest tube and drainage system. They should have adequate knowledge regarding the chest-tube position, controlling fluid evacuation, identifying when to change or empty the containers, and caring for the tube and drainage system during patient transport. By following a logical system of practice, the critical care nurse will be able to master the art of chest drainage with little difficulty (Durai et al ., 2010).

\section{Significance Of The Study}

Hutton et al., 2008, Johnny et al., 2010, and Lit et al., 2010 stated that there is lack of nurses' knowledge which may lead to a lot of complications due to bad nursing intervention for patients with chest tube such as blockage, infection, discomfort, pain and restricted mobility.

Moreover, this reflects the importance of nursing role because patients who need chest tubes are usually seriously ill and require advanced nursing care. Accordingly, vigilant and expert nursing care can prevent such serious complications.

Based on the results of Ibrahim (2011) study, he found that the majority of studied nurses at Ismailia University Hospital had statistically unsatisfactory level of knowledge related to 
chest tube. The need to develop training programs related to chest tube was suggested .Such program was expected to improve nurses' knowledge related to chest tube.

\section{AIM OF STUDY}

The aim of the present study was to evaluate the impact of an educational program on nurses' knowledge related to care of patient with chest tube.

Objectives:-

1- To assess nurses' knowledge related to care of patients with chest tube.

2- To develop a training program for nurses related to care of patients with chest tube.

3- To implement the training program.

4- To evaluate the effect of the implemented training program on the knowledge related to care of patients with chest tube.

Research Hypothesis:

Knowledge of nurses attending educational program related to care of patients with chest tube would be improved.

\section{SUBJECTS AND METHODS}

Research Design: the design of this study was a quasi experimental design done to evaluate the impact of an educational program on nurses' knowledge related to care of patients with chest tube

Setting: This study was conducted in intensive cardiothoracic unit, cardiothoracic care unit and general surgical unit at Ismailia University Hospital.

Subjects: All available nurses working with patients with chest tube in intensive cardiothoracic unit, cardiothoracic care unit and general surgical unit at Ismailia University Hospital (30 nurses) so the sample was convenient.

Tool for data collection:-

((Nurses' knowledge questionnaire); It was developed by the researcher based on the review of related literature to evaluate nurse's knowledge related to care of patients with chest tube.

It compromised two parts:

Part I: it included items related to socio- demographic characteristics of the studied nurses as their names, ages, educational levels, departments, years of experience, attendance of undergraduate studying unit about chest tube or its nursing care and attendance of any training courses about intensive care, infection control and chest tube care postgraduate .

Part II: it included 6 items containing $\mathbf{8 0}$ questions, divided into two groups of questions a group of M.C.Q statements which included $\mathbf{4 0}$ questions classified as the following; 
anatomy \& physiology of respiratory system $(\mathbf{1 0} \mathbf{Q})$, indications of chest tube $(\mathbf{8} \mathbf{Q})$, care of chest tube (5 Q) and problems associated with chest tube (17 Q) and a group of true \& false statements which included 40 questions regarding infection control (8 Q), data recording (16 Q) and discharge health education (16 Q). Nurses' responses were calculated as the right answer took one score and the wrong answer took zero .

\section{Scoring system:}

As regard nurse's knowledge each correct answer was scored one and wrong answer was scored zero

- The total nurses answered score were summed up then converted into percentage.

- Total nurses knowledge calculated as the following:

- All values $>75 \%$ were considered satisfactory

- All value $<75 \%$ were considered unsatisfactory

\section{Methods of study}

- An official permission was obtained from the directors of the specific hospital through an official formal letters from the dean of The Faculty Of Nursing Port Said University.

- The tool was tested for their content validity and clarity by 14 expertise in nursing and medical fields then appropriate modification was done accordingly(4 professor , 3 assistant professor, 6 lecturer from Alexanderia, Ain shams, Suez canal, Port said, Zigzags Universities).

- Informed consent was obtained from each nurse in the study after explaining its purpose and importance. Confidentially of the information was assured by the researcher.

- A pilot study was carried out after the development of the tools. It was carried out on $10 \%$ of the nurses working in intensive cardiothoracic care unit, cardiothoracic care unit and general surgical unit at Ismailia University Hospital to test the reliability and applicability of the tools of the study. The necessary modification was done based on the results of the pilot study. These nurses were excluded from the subject of research work to assure the stability of answers and performances.

- Following this pilot study, the process of data collection and implementation of educational program consumed 12 months from the beginning of May 2013 to the end of Febrauary 2013.

- The actual study was conducted through four phases: assessment phase, program development phase, implementation phase and evaluation phase. 


\section{I .Assessment phase:}

- In this stage, the researcher assessed nurses' learning needs using Nurses' knowledge questionnaire which was designed to assess nurses' knowledge related to providing care to patients with chest tube. The researcher introduced the sheet (Nurses' knowledge questionnaire )to each nurse and asked them to complete it.

- $\quad$ Also, the researcher assessed available place, time, equipment, supplies, instructional materials for conduction of the training program.

\section{Educational program development phase}

- The training program was developed based on the identified needs and demands of nurses gathered in phase $\mathbf{I}$, in the light of the most recent pertinent literature and based on Ibrahim master thesis (2011).This phase included the following;

\section{A-Formulation of objectives:-}

- $\quad$ The aim of the program was to improve nurses' knowledge related to care of patients with chest tube through:

-Improving nurses' knowledge related to care of patient with chest tube.

B- Contents: covered all areas about caring of patient with chest tube which include: anatomy and physiology related to chest tube, chest tube, common causes of air or fluid in the pleural space, indications for chest tube insertion, complication of chest tube, discharge health education.

\section{C-Planning of action:}

In this step the researcher designed a plan for a training program implementation. This plan included seven sessions was implemented in twelve week for each group. Each week included six groups of nurses. Each group contained five nurses from the same department. The time was spent in explanation with each group was 45 minutes and 75 minutes break between each group.

- Also, the program teaching strategy was determined by;

a-Choosing the appropriate teaching method which was in the form of (lecture, small group discussion)

b-Choosing the appropriate teaching media which was in the form of (handout, audiovisual material (lab)).

\section{D- Clinical area preparation:}

- Permission for conducting the study was taken from the head of nurse responsible for training after explaining the purpose, the time and the place of the study. Then she informed 
the head nurses of intensive cardiothoracic care unit, cardiothoracic care unit and general surgical unit to obtain cooperation.

- Nurses were informed to participate in the study according to their need. Some nurses refused to participate throughout the training program phases as the training program was not mandatory .Agreement on participation in the study was taken orally from nurses . The study was carried out only on nurses who participated in all stages of the training program.

- Many copies of Nurses' knowledge questionnaire and the training program were prepared by the researcher to facilitate learning and evaluation of the nurses' performance related to care provided to patients with chest tube.

\section{III -Program implementation:}

- At the beginning, the studied nurses were divided into six groups each group consisted five nurses, then each group was gathered at a conference room separately, the session was taken at available time to the gathered group which was during the working shift, time available for nurses working at the early shift was $12.30-1.15$ PM \& at the late shift $2.30-3.15$ PM . The training program was implemented for seven weeks at a rate of one session a week for each group. Each session took 45 minutes per day.

- At the beginning of the training program implementation, introduction to the training program and its importance, presentation of the training program plan and presentation of learning objectives of the training program were explained to each group separately.

- A copy of handout was given to each nurse to facilitate remembering the knowledge.

- The program was presented in clear and concise form using different teaching methods as small group discussions, lectures and appropriate teaching media as audiovisual material (lab).

- At the beginning of each session, it was suitable to start with a brief revision of what was given before. This was followed by statement of the objectives of the present session.

- Finally, the researcher gave her feedback starting with positive points then negative ones and any missing points or mistakes were corrected immediately to prevent other nurses from falling into the same mistakes. Also nurses were asked to give their feedback about the researcher.

\section{IV- Evaluation phase:}

The program outcome was evaluated by using Nurses' knowledge questionnaire, firstly immediately after program implementation, the second evaluation after three months and the third evaluation after six months. 
1. Immediately after program implementation, nurses' theoretical knowledge was evaluated by using Nurses' knowledge questionnaire.

2. The second evaluation after three months, the researcher informed nurses that she came to evaluate effectiveness of her program not to evaluate them and gave them the questionnaire to fill it.

3. The third evaluation after six months, also the researcher informed nurses that she came to evaluate effectiveness of her program not to evaluate them and gave them the questionnaire to fill it .

\section{Statistical analysis of data:}

1. The raw data were coded and transformed into coding sheets. The results were checked. Then, the data were entered into SPSS system files (SPSS package version 18) using personal computer. Output drafts were checked against the revised coded data for typing and spelling mistakes. Finally, analysis and interpretation of data were conducted.

2. The following statistical measures were used:

- Mean percent score was calculated for knowledge of nursing care offered for patients with chest tube among the studied nurses.

○ Descriptive statistics including frequency, distribution, mean, and standard deviation were used to describe different characteristics.

- Kolmogorov - Smirnov test was used to examine the normality of data distribution.

o Univariate analyses including: Student t-test and paired t-test were used to test the significance of results of quantitative variables. Mc Nemar test was used to test the significance of results of qualitative variables.

- The significance of the results was at the $5 \%$ level of significance.

\section{Limitation of the study}

- It was difficult to gather all the nurses form the same department at the same time to attend the program session. This problem was overcome by dividing the studied nurses in each shift in each department to two groups .

\section{RESULTS}

Table(1) shows the personal characteristics of the studied nurses. Regarding nurses' ages, two thirds of the studied nurses (63.3\%) were among the age of twenty years old to less than twenty five years old. As regards their marital status, it was found that the majority of them $(80 \%)$ were married. In relation to educational levels ,more than two thirds of the studied nurses $(70 \%)$ were having nursing diploma. Moreover, it is clear that equal percentages of 
studied nurses (33.3\%) working in cardiothoracic care unit, intensive cardiothoracic care unit and general surgical units attended the nursing educational program concerning care of patients with chest tube. Regarding nursing experience, more than half of the studied nurses (56.7\%) had experience on patients with chest tube ranging from five years to less than ten years. Furthermore, only one third of the studied nurses (30\%) had undergraduate training courses about nursing care of chest tube, while about two thirds of the studied nurses $(63.3 \%)$ did not have postgraduate training courses about infection control.

Table (2) shows the differences in studied nurses' knowledge related to care of patients with chest tube throughout the program intervention. Very high statistical significant difference in total score of studied nurses' knowledge was found between pre and post immediate program implementation and between post 6 months and post immediate program implementation were $\mathrm{P}<0.0001$.

Also very high statistical significant difference was found between pre \& post immediate program implementation in relation to anatomy and physiology of respiratory system, indications of chest tube ,care of chest tube, problems associated with chest tube, infection control, recording and discharge health education $(\mathrm{P}<0.0001)$ and between post immediate \& post 6 months program implementation was found in relation to anatomy and physiology of respiratory system, indications of chest tube ,care of chest tube, problems associated with chest tube and discharge health education were $\mathrm{P}<0.0001$.Moreover, this table shows that only a high statistical significant difference was found between post immediate and post 6 months after the program implementation in relation to problems associated with chest tube ( $\mathrm{P}=0.001)$.

Furthermore, this table shows a high statistical significant difference in relation to care of chest tube three months post program implementation ( $\mathrm{P}=0.008$ ) and a statistically significant difference in relation to discharge health education $(\mathrm{P}=0.016)$.

Table (3) shows the comparison between nurses' mean score of studied nurses related to care of patients with chest tube throughout the program intervention according to their characteristics. The only statistically significant difference was found between knowledge of studied nurses and their department of employment $(\mathrm{P} \leq 0.05)$ in favor of intensive cardiothoracic nurses as nurses working in intensive cardiothoracic unit had the highest means pre, post immediate, post three months and post six months of program implementation $(56.0 \pm 19.5,95.6 \pm 3.4,90.3 \pm 6.8,84.7 \pm 9.6$ respectively). Also, this table shows that the only statistically significant difference was found between studied nurses' knowledge and postgraduate training courses about infection control after three months post program implementation $(\mathrm{P}=0.024)$. 
Table (1): Personal characteristics of the studied nurses $(n=30)$.

\begin{tabular}{|l|c|c|}
\hline \multirow{2}{*}{ Personal characteristics } & \multicolumn{2}{|c|}{$\begin{array}{c}\text { Studied nurses } \\
(\mathbf{n}=\mathbf{3 0})\end{array}$} \\
\cline { 2 - 3 } & No. & $\%$ \\
\hline Age (years) & 2 & 6.7 \\
Less than 20 & 19 & 63.3 \\
$20-<25$ & 6 & 20.0 \\
$25-<30$ & 3 & 10.0 \\
$30-<35$ & & \\
\hline Marital status & 6 & 20.0 \\
Single & 24 & 80.0 \\
Married & & \\
\hline Educational level & 21 & 70.0 \\
Nursing diploma & 9 & 30.0 \\
Technical institute & & \\
\hline Department of employment & 10 & 33.3 \\
Intensive cardiothoracic unit & 10 & 33.3 \\
Cardiothoracic care unit & 10 & 33.3 \\
General surgery units & & \\
\hline Duration of experience with patients with chest tube (years) & 4 & 13.3 \\
Less than 5 & 17 & 56.7 \\
5-<10 & 9 & 30.0 \\
10 years or more & & \\
\hline Undergraduate training courses about nursing care & & \\
of chest tube & 9 & 30.0 \\
Yes & 21 & 70.0 \\
No & & \\
\hline Postgraduate training courses about infection control & 11 & 36.7 \\
Yes & \multicolumn{2}{|c|}{63.3} \\
\hline No & \\
\hline
\end{tabular}




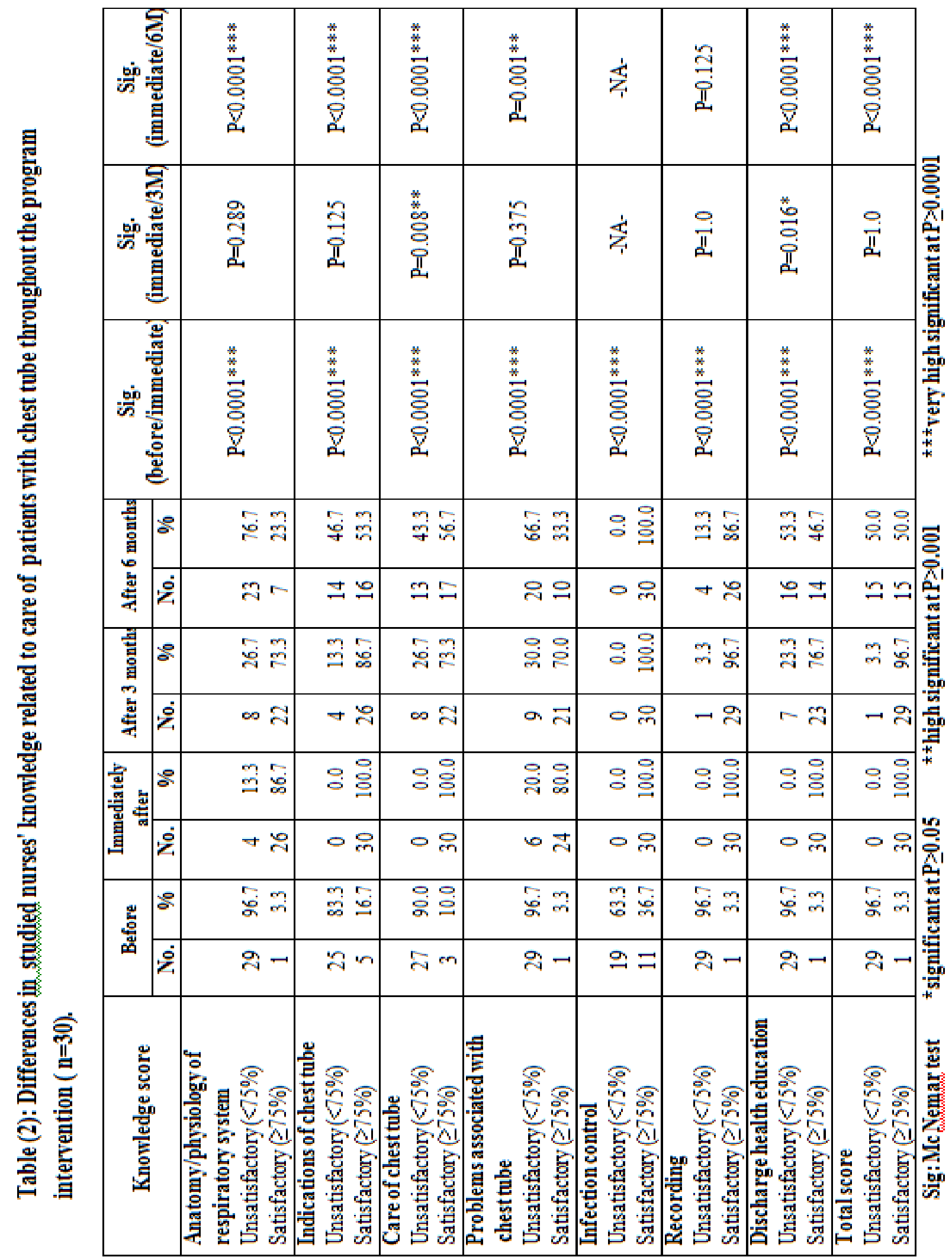




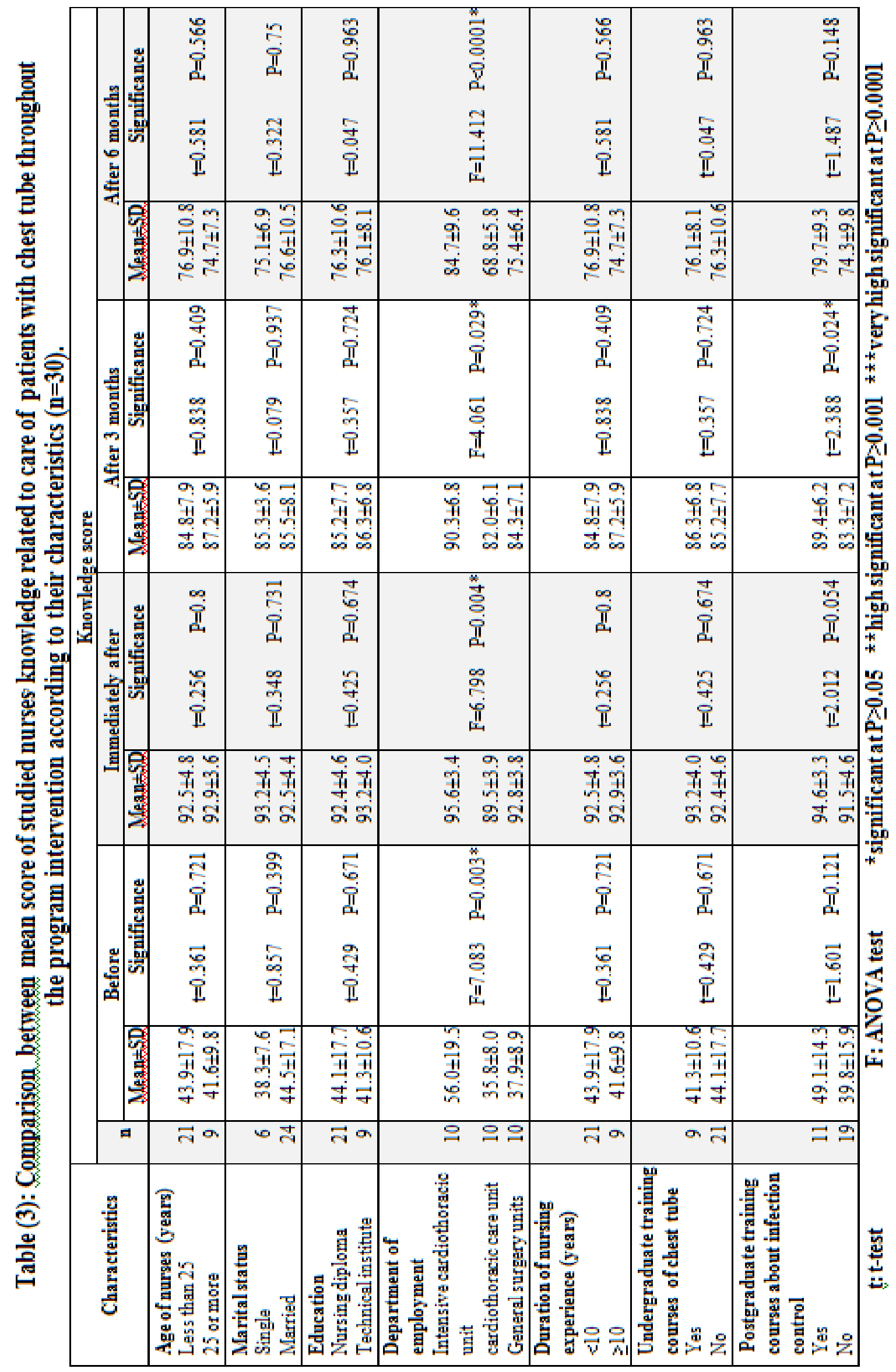




\section{DISCUSSION}

Lack of evidence-based nursing care and insufficient training has resulted in uncertainty and knowledge deficit on an important aspects of chest tube care, exposing patients to avoidable complications. Moreover, poor instructions to nurses from doctors following chest tube insertion further compromises patient care. A carefully designed and implemented care bundle to guide nurses through chest tube management could significantly lower postinsertion complications (Fremlin, 2011).

The results of the present study revealed that the majority of studied nurses their ages ranged from twenty years old to less than twenty five years old and they were graduated from secondary nursing school. These results might be due to that the Faculty of Nursing at Ismailia started only 7 years ago so the number of graduates up-till now is not enough to cover all units. So, these graduates worked only in intensive care unit, or as administrator. This result went in line with Ahmed (2003) who stated that the majority of the nursing manpower in Egypt were graduated from diploma school and it expected that nowadays they are employed in all nursing service. However, they added that, the trends was -at the timethat graduates from The Faculty of Nursing employed in areas were geared to care for patients in need for high technology care.

Moreover, the findings of the present study indicated that the majority of studied nurses did not have any undergraduate training courses about chest tube care as they graduated from secondary nursing school and about half of them had less than 10 years experience. Also, they did not attend any postgraduate training program related to chest tube or intensive care. While only one third of them attended training program related to infection control.

In this respect, American Association of colleges of nursing (AACN) encourages employers to foster practice environments that embrace lifelong learning and offer incentives for registered nurses (RNs) seeking to advance their education to the baccalaureate and higher degree levels. they also encourage nurses with Bachelor of Science in Nursing (BSN) graduates to seek out employers who value their level of education and distinct competencies (AACN, 2014).

Also, these results are in agreement with Ibrahim (2013) who stated that the majority of nurses working at Ismailia University Hospital; their ages were less than twenty five years old, graduated from secondary nursing school, and most of them did not attend any postgraduate training programs related to infection control. 
As regards nurses' knowledge about chest tube before program implementation in the current study, nearly all studied nurses had high statistically significant unsatisfactory total basic knowledge related to chest tube as anatomy \& physiology of respiratory system, indications for chest tube, care of chest tube, problems associated with chest tube , infection control, recording data, discharge health education and total knowledge score .

This result might be due to that there was no source for acquiring knowledge from doctors, head nurses, attending training courses and even no guidelines or any protocol of nursing intervention about care of patient with chest tube in any studied unit. Also, this finding is in accordance with Charnock and Evan (2001) who conducted a randomized controlled trial on nursing management of chest tube drainage. The study results highlighted the lack of research on most aspects of the nursing management of patients with chest tube. As there was a lack of knowledge among the nursing staffs in many aspects of chest tube management. In this study, the researcher pointed out to the need for rigorous research in many areas of the nursing management of chest tube.

Furthermore, this result was supported by Lehwalt \& Timmins (2005) who conducted an exploratory descriptive survey on nurse's knowledge on chest tube care. The study results showed that there appears to be a lack of consensus among nurses on the major principles of chest tube management. Many decisions tend to be based on personal factors rather than sound clinical evidence. This inconsistency of treatment regimes, together with the lack of evidence-based nursing care, creates a general uncertainty regarding the care of patients with chest tubes. He recommended that nurses must be supported by local practice development and through personal portfolio use to identify gaps in knowledge and seek appropriate training and resources.

Moreover, the current study revealed that there was a highly statistically significant improvement immediately after program intervention in all nurses' knowledge score related to the anatomy and physiology of the respiratory system , indications for chest tube, care of chest tube, problems associated with chest tube, infection control, recording data, discharge health education and total knowledge score.

This results is in agreement with Ramya and Neethu (2013) who found that extreme statistically significant difference is found between the total knowledge score of pre and post test revealing effectiveness of Self Instructional Module on Nursing Management of Patients with Chest Tube Drainage for Staff Nurses Working in a Selected Hospital of Odisha, The Instituate of Medicine, (2010) and Skees, (2010) stated that for professional nurses, continuing education is essential to safe and effective nursing care. The amount of knowledge 
required to take care of critically ill patients cannot be obtained simply through experience on the unit or at the bedside.

In the present study, at the first follow up, three months post program intervention, there was a decline but not statistically difference was found in nurses' knowledge related to the anatomy and physiology of the respiratory system, indications for chest tube, problems associated with chest tube, infection control, recording data and total knowledge score but it was still higher than pre program intervention .

This result reflected two aspects ,the first was effectiveness of the training program as their knowledge was still higher than pre program intervention ,the second was deficiency in nurses' retention to knowledge which indicates necessity for planning refreshed training courses every six months.

This went in the line with Sobh (2010) who revealed poor retention of nurses' knowledge after three months of program intervention .So based on his study and others' experience, he recommended that three months has become the best re-testing interval suggested by the international guidelines.

Also, there was a statistically significant difference at the first follow up, three months post program intervention related to nurses' knowledge about care of chest tube and discharge health education. This might be due to difficulty in applying these knowledge in practice which reflects the need of nurses' knowledge reinforcement and strict supervision for applying this knowledge in practice.

In this respect Blot, et al., (2007) indicated that to improve retention theoretical knowledge is needed and to achieve better outcomes frequent theoretical and practical training are needed and give a chance to repeat the difficult parts of the program.

Concerning the second follow up, six months post program intervention in this study although there was obvious decline in nurses' knowledge related to the anatomy and physiology of the respiratory system, indications for chest tube, care of chest tube, problems associated with chest tube, discharge health education and total knowledge score between six months and immediate post program intervention but nurses' knowledge was still higher than pre program intervention.

This finding is supported by Eldosoky (2008) who recommended that periodic refreshing courses should be planned and implemented for nurses every six months to one year The findings of the present study revealed that there was a relation between knowledge of studied nurses and their department of employment throughout the program intervention phases as studied nurses working in intensive cardiothoracic department gained higher knowledge score 
than nurses working in cardiothoracic care unit and general surgical units. This might be due to that they were more specialized in this area as most of patients they dealt with had chest tube. Most of them were graduated from technical health institute studied chest tube and its nursing care and they only needed refreshment of their knowledge

Also, there was a statistically significant difference between knowledge of studied nurses three months post program implementation and postgraduate training courses about infection control. This means that studied nurses who attended postgraduate training courses about infection control gained high knowledge score and their level of knowledge was still high, but studied nurses whom did not attend the training infection control program as their level of knowledge decreased three months later. This finding pointed to the successful effect of the implemented training program .

This finding is in disagreement with Ramya and Neethu (2013) who conducted a study on effectiveness of self instructional module on nursing management of patients with chest tube drainage for staff nurses working in a selected Hospital of Odisha. They found no significant relation between pre test knowledge score of nurses when compared to demographic variables.

In conclusion, the results of the present study revealed a statistically significant improvement of nurses' knowledge was found regarding care of patients with chest tube throughout the program phases. Based on this finding, the research hypothesis was fulfilled.

\section{RECOMMENDATIONS}

\section{Based on the results of this study, the following recommendations are suggested:}

\section{Recommendations for nurses:-}

1. Importance of presence of protocol related to care of patients with chest tube.

2. Upgrading nurses' knowledge about caring of patients with chest tube through:

- Encouraging nurses to attend national and international congresses, seminars, symposia and workshops regularly about chest tube $\&$ care of patients with chest tube.

- Regular continuous educational program plan about chest tube \& its management should be designed to nurses working in ICU at least every six months for enhancing nurses' knowledge and practice to achieve high quality of care.

- Encouraging nurses dealing with patients with chest tube to attend regular formal inservice educational programs about chest tube.

- Developing a system of periodical evaluation for nurses to determine strategies of upgrading their knowledge and enhancing their practice. 
- Chest tube training program should be mandatory for newly employed nurses.

- Nurses involved in patient care should have a valid chest tube care certification and renew it regularly at least every one year.

3. Nursing school curriculum must include all items about chest tube care including; definition, indications, insertion, chest drainage systems, problems associated with chest drainage system, complications of chest tube, role of nurses towards patients with chest tube and chest tube removal.

4. Studying the impact of educational programs on chest tube continuously using a wide probability sample in different areas to monitor improvement in nurses' performance and points of weakness for developing more educational program to nurses dealing with patients with chest tube to improve nurse's performance.

\section{REFERENCES}

1. Ahmed H M.(2003): Assessment of nurses' knowledge and practice about postoperative wound infection. Master thesis, Faculty Of Nursing, Suez Canal University. Egypt.

2. American Association Of Colleges Of Nursing.(2014): The impact of education on nursing practice. Available at Rosseter@Aacn.Nche.Edu. Accessed at5/6/2014.

3. Blot S I., Labeau S. ,Vandijck D., Aken P V. and Claes B.(2007):Evidence-based guidelines for the critical care nurses related to the mechanical ventilation: results of a knowledge test among intensive care nurses-intensive care medicine;8(33).

4. Charnock Y. and Evans D. (2001): Nursing management of chest drains: systemic review.Aust Crit Care; 14(4):156-160.

5. Durai R. Hoque H. and Davies W.(2010): Managing a chest tube and drainage system. AORN Journal ; 91( 2): Pp 275-283.

6. Eldosoky E I.(2008): Effect of a training program for nurses about preventive measures of deep vein thrombosis. Dectorate thesis, Faculty of nursing ;Suez Canal University. Egypt.

7. Fremlin G., Baker R., Walters G. and Fletcher T.(2011): Are nursing staff sufficiently educated and competent in managing patients with a chest drain?. Journal Of British Thoracic Society; 66(8): P.1.

8. Ibrahim M H.(2013):Effect of training program on nurses'performance regarding infection control in caring for patients with peripheral intervenous cannula. Dectorate thesis, Faculty Of Nursing; Suez Canal University. Egypt. 
9. Ibrahim N M. (2011):Assessment the nurses' performance in providing care to patients undergoing chest tube in Suez Canal University hospital. Un published aster Thesis, Faculty Of Nursing; Suez Canal University. Egypt.

10. Institute Of Medicine.(2010 ):Redesigning continuing education in the health professions. Available at www.Nap.Edu. Accessed at 7/3/2014.

11. Lehwalt D. and Timmins F.(2005): Nurses' knowledge of chest drain care, an exploratory descriptive survey. J Nursing Critical Care; 10(4): P.p 192-200.

12. Rajan $\quad S \quad C$. (2013): Tube thoracostomy management. Available at Emedicine.Medscape.Com. Accessed at 17/10/2013.

13. Ramya K R. and Neethu J.(2013): Effectiveness of self instructional module on nursing management of patients with chest tube drainage for staff nurses working in a selected hospital of Odisha. International Journal Of Nursing Education; 5( 2).P.p.155-159.

14. Skees J. ( 2010):Continuing education, a bridge to excellence in critical care nursing. Crit Care Nurs Q;33:P.p.104-116.

15. Sobh D E.(2010):Effect of an educational program about the care of mechanically ventilated patients on the knowledge and skill performance in intensive care units of hospitals in Port Said City. Doctorate Thesis, Faculty of nursing; Port Said University. Egypt. 16. Shalmovitz ZG. (2011): Tube thoracostomy. Available at Emedicine. Medscape. Com. Accessed at 23/9/2013. 


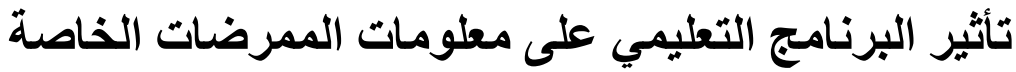

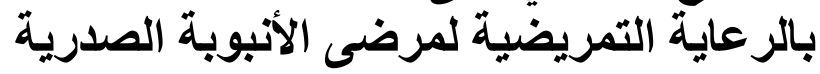

$$
\text { د/ نبيلة أحمد بدير - د/ أمل بكر أبوا العطا - م.م نهى محمد ابر اهيم }
$$

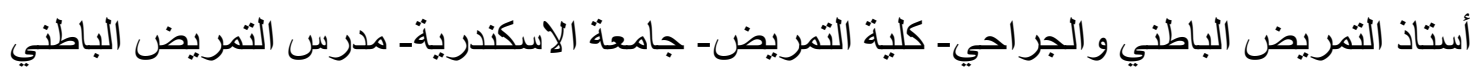
و الجر احيـ كلية التمريض- جامعة بورسعيد- مدرس مساعد التمريض الباطني و الجر احي- كلية

التمريض- جامعة بورسعيد

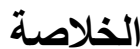

تعتبر الأنبوبة الصدرية من الإجراءات العلاجية الهامة والثائعة للعديد من الاضطر ابات الرئوية، مما يكون لها الأثر في إنقاذ حياة المريض حيث أن استخدامها يساعد على تمدد الرئتين وتتفس المريض بشكل طبيعي. تهدف هذه الدراسة إلى تقييم تأثثير برنامج تعليمي للممرضات عن معلومات الممرضات

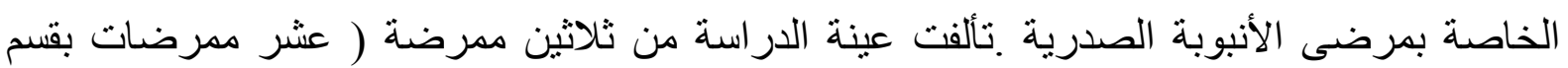
عناية قلب وصدر و عشر ممرضات بقسم رعاية قلب وصدر و عثر ممرضات بقسم الجراحة العامة ) يعملن في مستشفي الإسماعيلية الجامعي ـ تم تجميع المعلومات الخاصة بالدراسة باستخدام استمارة استبيان لمعرفة معلومات الممرضات عن الرعاية التمريضية لمرضى الأنبوبة الصدرية.تم إعداد البرنامج التعليمي بعد مراجعة المواد العلمية.أظهرت النتائج أن جميع الممرضات ليس لايهن المستوى الئرئ المرضى من المعلومات قبل تنفيذ البرنامج، أظهرت نتائج الدراسة تحسنا واضحا في معلومات الممرضات بعد تنفيذ البرنامج كما أظهرت النتائج انخفاض في معلومات الممرضات بعد ثلاثة أثنهر وبعد ستة أثنهر من تنفيذ البرنامج وتتضمن الدارسة تحسنا ايجابيا ملحوظا في معلومات الممرضات تجاه مرضى الأنبوبة الصدرية بعد تنفيذ البرنامج مباثرة وخلال المتابعة الثانية والثالثة. توصى الار اسة بعمل بر امج تعليمية منتظمة ومستمرة وذلك لتحسين معلومات الممرضات مما يحقق رعاية ذات جودة عالية. الكلمات الدالة: البرنامج التعليميـ معلومات ـ الممرضات ـ الرعايةـ الأنبوبة الصدرية 